\title{
MRSA decolonization failure-are biofilms the missing link?
}

Frank Günther ${ }^{1}$, Brigitte Blessing ${ }^{1}$, Evelina Tacconelli, ${ }^{2,3}$ and Nico T. Mutters ${ }^{1,2^{*}}$

\begin{abstract}
Background: Device-associated infections due to biofilm-producing methicillin-resistant Staphylococcus aureus (MRSA) have been recently associated with the failure of antibiotic treatment and decolonization measures. The goal of our study was to evaluate the extent to which the formation of biofilms influenced the efficacy of topical decolonization agents or disinfectants such as mupirocin (MUP), octenidine (OCT), chlorhexidine (CHG), polyhexanide (POL), and chloroxylenol (CLO).

Methods: Bacterial killing in biofilms by the disinfectants and MUP was determined as the reduction [\%] in metabolic activity determined by a biofilm viability assay that uses kinetic analysis of metabolic activity. The test substances were diluted in water with standardized hardness (WSH) at $25^{\circ} \mathrm{C}$ at the standard concentration as well as half the standard concentration to demonstrate the dilution effects in a practical setting. The tested concentrations were: CHG 1\%, 2\%; OCT 0.1\%, 0.05\%; PH 0.04\%, 0.02\%; and CLO 0.12\%, 0 . $24 \%$. A test organism suspension, $1 \mathrm{~mL}$ containing $\sim 1 \times 10^{9}$ bacterial cells $/ \mathrm{mL}$, and $1 \mathrm{~mL}$ of sterile WSH were mixed and incubated for six different exposure times (15 s, 1, 3, 5, 10 and $20 \mathrm{~min})$ after the test substance was added.

Additionally, the bactericidal effects of all substances were tested on planktonic bacteria and measured as the $\log 10$ reduction.

Results: The disinfectants OCT and CHG showed good efficacy in inhibiting MRSA in biofilms with reduction rates of $94 \pm 1 \%$ and $91 \pm 1 \%$, respectively. POL, on the other hand, had a maximum efficacy of only $81 \pm 7 \%$. Compared to the tested disinfectants, MUP showed a significantly lower efficacy with $<20 \%$ inhibition $(p<.05)$. Bactericidal effects were the greatest for CHG (log10 reduction of 9.0), followed by OCT (7.7), POL (5.1), and CLO (6.8). MUP, however, showed a very low bactericidal effect of only 2.1. Even when the exposure time was increased to 24 h, $2 \%$ MUP did not show sufficient bactericidal effect.

Conclusions: Our data provide evidence that OCT and $\mathrm{CHG}$ are effective components for disinfection of MRSA-biofilms. On the other hand, exposure to MUP at the standard concentrations in topical preparations did not effectively inhibit MRSA-biofilms and also did not show adequate bactericidal effects. Combining an MUP-based decolonization regimen with a disinfectant such as OCT or CHG could decrease decolonization failure.
\end{abstract}

Keywords: MRSA, Decolonization, Biofilm, Chlorhexidine, Octenidine, Mupirocin, Polyhexanide, Chloroxylenol, Infection control

\footnotetext{
* Correspondence: nico.mutters@med.uni-heidelberg.de

${ }^{1}$ Department of Infectious Diseases, Heidelberg University Hospital, Im

Neuenheimer Feld 324, 69126 Heidelberg, Germany

${ }^{2}$ Division of Infectious Diseases - Department of Internal Medicine I,

Tübingen University Hospital, Tübingen, Germany

Full list of author information is available at the end of the article
} 


\section{Background}

Methicillin-resistant and biofilm-forming Staphylococcus aureus (MRSA) isolates have become a common clinical problem [1]. In recent years, MRSA incidences seemed to be decreasing, and the focus of infection control specialists was multidrug-resistant Gram-negative bacteria [2-4]. However, Public Health England recently reported an alarming 26\% increase in MRSA bloodstream infections [5]. Although the rise in numbers coincided with the Department of Health's change in policy on screening for MRSA, from universal to targeted screening, it underlines the fact that MRSA cannot be considered "out of the picture". The formation of biofilms as a reaction to therapeutic interventions, which can lead to increased antimicrobial resistance and a higher chance of treatment failure, is being increasingly recognized as an infection control problem [6, 7]. Accordingly, treatment and decolonization failure occur more frequently when topical drugs like mupirocin are used against biofilm-forming microorganisms [8-12].

The organization of bacteria into biofilms is the common mode of bacterial survival, since this form increases their ability to withstand antibiotics, disinfectants, and host responses. Biofilm formation is a multifarious, controlled bacterial process that induces many additional functional and phenotypic alterations, including loss of motility, reduced growth rate, increased surface adhesion, as well as an altered susceptibility to the host response [13-17]. An association with biofilm formation has been reported for many hospital-acquired infections, such as urinary tract and catheter-related bloodstream infections as well as infections of implanted medical devices including indwelling catheters, artificial heart valves, orthopedic prostheses, or osteosynthesis materials [7, 18-24]. Colonization with MRSA is associated with a high risk of acquiring an MRSA infection during hospital stays $[25,26]$. Decolonization may reduce the risk of MRSA infection in individual carriers and prevent transmission to other patients [25]. However, the most commonly used agent for decolonization, mupirocin, comes with a considerable risk of resistance if widely employed [26]. There have been many other attempts to eradicate carriage, mostly with topical agents, but success rates have not been consistent or applicable to all populations [26], and even mupirocin decolonization success rates can be low [25]. Many international guidelines (i.e., in Germany, Ireland, Netherlands, Slovenia) already state that attempts at decolonization are unlikely to be successful in patients with chronic skin conditions, ulcers, or in-dwelling catheters [27-30]. Some studies, however, showed that decolonization can be effective in patients with lines and catheters [25] and that the inability to decolonize was most closely associated with failure to use a standardized decolonization protocol [31].
However, to our knowledge, no study has been able to identify a consistent subgroup of patients at higher risk for decolonization failure. Perhaps, the focus has been on the wrong variable in the equation, and the reason for decolonization failure is not the patient but the bacterium and its biofilm-forming capacities. Alarmingly, one study on biofilm formation among MRSA nasal carriers showed that all of the isolated MRSA had the ability to form biofilms [7]. The goal of our study, therefore, was to evaluate the extent to which MRSA biofilms are influenced by the use of the topical decolonization antibiotic MUP and the widely used topical disinfectants, i.e., octenidine (OCT), chlorhexidine (CHG), polyhexanide (POL), and chloroxylenol (CLO).

\section{Methods}

\section{Bacterial isolates}

To ensure practical relevance, clinical MRSA isolates, as well as American Type Culture Collection (Manassas, VA, USA; ATCC $^{\circ}$ ) control strains, were tested in this study. Clinical isolates were recovered as follows: screening swab samples were inoculated on Columbia 5\% sheep blood agar plate (BD Diagnostics, Sparks, USA) and chromogenic plates for MRSA detection (ChromAgar MRSA II, BD) and incubated under aerobic conditions for $48 \mathrm{~h}$ at $36{ }^{\circ} \mathrm{C}$. If growth on chromogenic plates was detected, identification by matrix-assisted laser desorption ionization-time-of-flight mass spectrometry (MALDITOF MS) (Bruker Daltonics, Bremen, Germany) was performed [32]. Agglutination with Pastorex ${ }^{\bullet}$ StaphPlus (Alere, Jena, Germany) was performed to confirm $S$. aureus growth. Susceptibility testing was performed by VITEK2 (bioMérieux) and results were interpreted according to EUCAST breakpoints. Biofilm-forming capacities of each isolate were determined by the crystal violet staining technique (data not shown). Six representative isolates with significant biofilm-forming capacity compared to the standard disinfectant efficacy test isolate ATCC $^{\circ} 6538^{\text {ma }}$, according to ATCC $^{\ominus}$ product sheet, were selected and used for further testing.

\section{Preparation of antimicrobials and neutralizer}

For standardization of experimental conditions, in each experiment, water of standardized hardness (WSH) was prepared with a total hardness of $300 \mathrm{ppm}\left(\mathrm{CaCO}_{3}\right)$ with $0.119 \mathrm{~g} / \mathrm{l}$ magnesium chloride (Carl Roth, Karlsruhe, Germany), $0.277 \mathrm{~g} / \mathrm{l}$ calcium chloride (Carl Roth), and $0.28 \mathrm{~g} / \mathrm{l}$ sodium hydrogen carbonate (Carl Roth). WSH at a pH of $7.0 \pm 0.2$ at $25{ }^{\circ} \mathrm{C}$ was used as a diluent. Tryptic soy broth (TSB) containing lecithin, Tween 80 , histidine, and sodium thiosulfate neutralizing agent (all from Merck Millipore, Darmstadt, Germany) (LTHTh) was used in both treatment and control groups, immediately following disinfection according to the manufacturer's instructions. 
The media and neutralizers used in this study were approved for effective neutralization of the applied disinfectants prior to the experiments (data not shown).

\section{Biofilm viability assay}

The MRSA isolates were cultured on Columbia blood agar plates at $37{ }^{\circ} \mathrm{C}$ for $12 \mathrm{~h}$. Bacterial killing in biofilms was determined as reduction [\%] in metabolic activity using a kinetic biofilm viability assay as previously described [33]. Briefly, the test substances were diluted in WSH at $25{ }^{\circ} \mathrm{C}$ at the standard concentration as well as half the standard concentration to demonstrate the dilution effects in a practical setting. For testing of antimicrobial effects on the bacterial metabolic activity in biofilms, the antimicrobial substances were diluted in WSH at standard working concentrations $0.05 \%$ and $0.1 \%(w / v)$ for OCT (TCI, Eschborn, Germany), $1 \%$ and 2\% (w/v) for CHG (Sigma Aldrich, Taufkirchen, Germany), $0.02 \%$ and $0.04 \%(\mathrm{w} / \mathrm{v}$ ) for POL (Fagron, Barsbuettel, Germany), $0.12 \%$ and $0.24 \%$ (w/v) for CLO (Sigma Aldrich), and $1 \%$ and $2 \%(\mathrm{w} / \mathrm{v})$ for MUP (Fagron). Each preparation was applied to the prepared biofilms for different exposure times of $15 \mathrm{~s}, 1,3,5,10$ and $20 \mathrm{~min}$ at $37^{\circ} \mathrm{Cfor}$ the OCT, CHG, POL, and CLO solutions. Prolonged exposure times of up to $3.5 \mathrm{~h}$ were used for MUP to analyze the different mode of action of this substance. To take into account the different mode of action of MUP compared to disinfectants, extended exposure times of up to $3.5 \mathrm{~h}$ were used for this substance adapted to simplified testing protocols for determination of bactericidal activity on Staphylococcus aureus isolates as previously described [34]. After exposure, the remaining metabolic activity in the biofilm was measured. Biofilms exposed to WSH alone (without supplements) served as a control for $100 \%$ viability or $0 \%$ inhibition. The bacterial killing by the disinfectants in the biofilms was determined as the reduction [\%] in metabolic activity as compared to the untreated controls.

\section{Live/dead staining of biofilms}

To analyze the killing effects on the bacterial cells in biofilms, biofilms were cultured on glass coverslips (Carl Roth). After incubation, biofilms were washed twice in a $0.9 \% \mathrm{NaCl}$ solution. Then, $100 \mu \mathrm{L}$ M63 minimal medium consisting of $0.015 \mathrm{M}$ ammonium hydrogen sulfate (Carl Roth), $0.1 \mathrm{M}$ potassium dihydrogen sulfate (Sigma-Aldrich, Steinheim, Germany), $1.8 \mu \mathrm{M}$ iron sulfate heptahydrate (Carl Roth), $1 \mathrm{mM}$ magnesium sulfate heptahydrate, $2 \mathrm{ml} / \mathrm{L}$ glycerol (VWR Chemicals, Darmstadt, Germany) and $1 \mathrm{~g} / \mathrm{L}$ casein hydrolysate standard (Carl Roth)containing disinfectants in different concentrations was added, and the biofilms were incubated for up to $2 \mathrm{~h}$ at $37{ }^{\circ} \mathrm{C}$. After incubation, biofilms were washed twice in $0.9 \% \mathrm{NaCl}$ solution and stained using the LIVE/DEAD BacLight Bacterial Viability Kit (Molecular Probes, Leiden, Netherlands) according to the manufacturer's instructions. Stained biofilms were analyzed after mounting on object slides by using a BZ 8100 fluorescence microscope (Keyence, Neu-Isenburg, Germany) in the green fluorescent band for Syto 9 staining of dead and living bacterial cells, and in red fluorescent band for selective propidium iodide staining of dead cells or cells with disturbed cell integrity; therefore, yellow color in the overlay image is indicative of dead bacteria in the biofilm.

\section{Determination of bactericidal activity}

For determination of bactericidal effects, the antimicrobial substances were diluted in WSH at standard

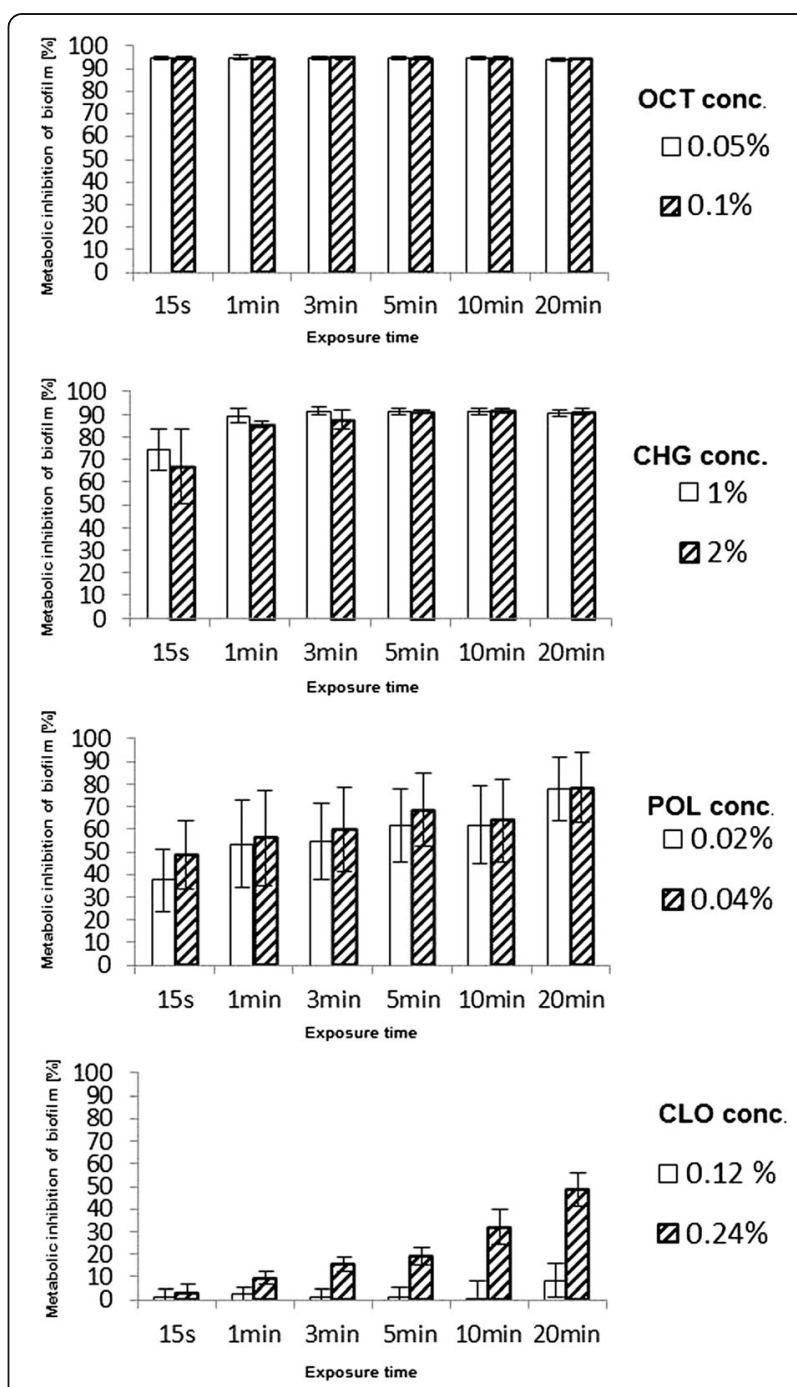

Fig. 1 Disinfectant efficacy on MRSA-biofilms Reduction of metabolic activity (\%) in bacterial biofilms \pm standard deviation (SD) after disinfectant treatment at different concentrations and for varying exposure times, determined by a kinetic metabolic assay 
working concentrations $0.1 \%(\mathrm{w} / \mathrm{v})$ for $\mathrm{OCT}, 2 \%$ for CHG, $0.04 \%(w / v)$ for POL, $0.24 \%(w / v)$ for CLO, and $2 \%(\mathrm{w} / \mathrm{v})$ for MUP, and at least $1 \times 10^{9}$ bacterial cells were added for different exposure times. Each sample was tested for the surviving bacterial count by membrane filtration of the disinfectant solution through a $0.45-\mu \mathrm{m}$ nitrocellulose membrane (Sartorius Stedim, Göttingen, Germany) followed by rinsing three times using $100 \mathrm{ml}$ of a $\mathrm{NaCl}$-peptone solution (Becton Dickinson, Heidelberg, Germany) for removal of remaining disinfectant. Afterwards, the filters were transferred to Caso Agar containing LTHTh as a neutralizer (Merck Millipore, Darmstadt, Germany). The neutralization and washing steps were validated for effective neutralization of the tested disinfectants prior to this study (data not shown). The media were incubated for $48 \mathrm{~h}$ at $37{ }^{\circ} \mathrm{C}$ and then checked for microbial growth. Colony forming units (CFUs) were counted and the $\log 10$ reduction factor $\left(\mathrm{LRF}_{10}\right)$ was calculated compared to the untreated controls as a measure of the bactericidal effect.

\section{Statistics}

For descriptive purposes, arithmetic mean value, standard deviation, median, interquartile range, and cumulative frequencies were calculated as appropriate. $P$ values of $\leq .05$ were considered statistically significant. Statistical analysis was performed using the SPSS ver. 21.0 statistical package (SPSS, Chicago, IL).

\section{Results}

The effects of the different disinfectants on metabolic activity in established MRSA biofilms were tested using a kinetic metabolic assay (Fig. 1) [33]. OCT showed moderate efficacy in inhibiting microbial metabolic activity with $94 \pm 1 \%$ inhibition after only $15 \mathrm{~s}$ of exposure and at a concentration of $0.05 \%$. The overall efficacy of OCT on MRSA biofilm inhibition was not significantly changed due to modifications of the concentration used, ranging from $0.05 \%$ to $1 \%$, or due to modifications of the exposure time, ranging from $15 \mathrm{~s}$ to $20 \mathrm{~min}$. The CHG solution showed a efficacy of $91 \pm 1 \%$ in inhibiting microbial metabolic activity after $3 \mathrm{~min}$ of exposure to a $1 \%$ CHG solution. Furthermore, after 1 min of exposure, there was no significant increase in efficacy of CHG on MRSA biofilms for the tested concentration range. POL, in contrast, yielded a lower overall medium efficacy of inhibition of metabolic activity in biofilms of $65.4 \pm 11 \%$, while the efficacy was strongly dependent on the applied exposure time. CLO showed the lowest efficacy of $15.8 \pm 27 \%$. Additionally, the efficacy of CLO was strongly dependent on the applied exposure time and concentration.

On the other hand, the antibiotic MUP showed detectable efficacy in inhibiting metabolic activity in MRSA biofilms after short exposure times (Fig. 2). To rule out that the lack of efficacy is caused by the different mode of action of MUP, namely the inhibition of bacterial protein synthesis, the exposure times for MUP on the MRSA biofilms were extended to up to $3.5 \mathrm{~h}$. Even after

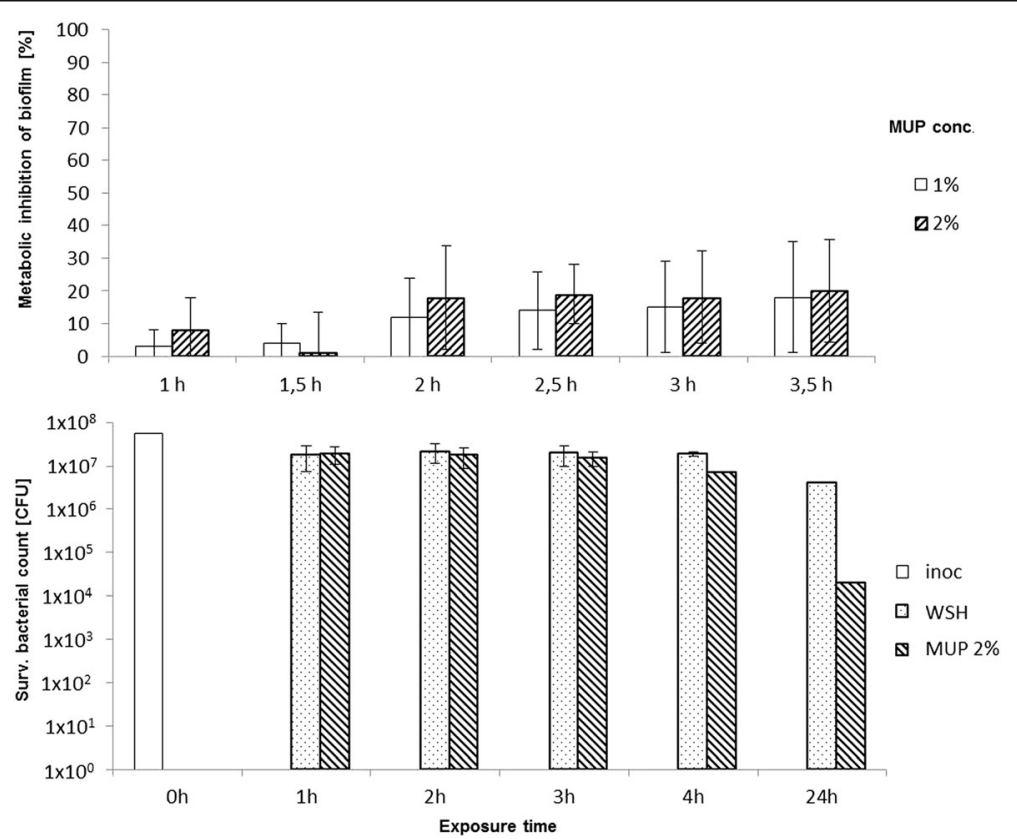

Fig. 2 MUP efficacy on MRSA-biofilms and planktonic bacteria Upper panel: Reduction of metabolic activity (\%) in bacterial biofilms \pm SD after MUP treatment at different concentrations and varying exposure times, determined by a kinetic metabolic assay. Lower panel: Bactericidal activity of a $2 \%$ MUP solution on planktonic MRSA, shown as reduction of cell counts [CFU] compared to untreated controls in WSH 
$3.5 \mathrm{~h}$ of exposure to $2 \%$ MUP solution, the level of metabolic inhibition of the bacteria in the MRSA biofilms did not exceed $20 \%$, while significant inhibition $(p<$ $0.05)$ was reached after at least $2 \mathrm{~h}$ of. Taken together, 2\% MUP showed between 1 and 20\% inhibition of the metabolic activity of MRSA biofilms after exposure times of up to $3.5 \mathrm{~h}$ (Fig. 2).

Exposure of biofilms to OCT and CHG solutions led to extensive damage of bacterial cell integrity as indicated by positive propidium iodide staining (Fig. 3), whereas the viability of bacteria in biofilms and the cell integrity of the same strain and maturation state were only weakly affected by POL and CLO and only slightly affected by exposure to $2 \%$ MUP for $2 \mathrm{~h}$, similar to that seen in the exposure to WSH only. Additionally, no restrictions of biofilm permeation could be detected for the OCT- and CHG-mediated biofilm killing effects as indicated by the fact that the damage to the biofilm was not restricted to the outside layer.

Regarding the bactericidal effects, each of the four tested disinfectants, OCT, CHG, POL, and CLO, reached a $\mathrm{LRF}_{10}$ using planktonic MRSA of at least 4 after $1 \mathrm{~h}$ of exposure. In contrast, exposure of MRSA to a $\%$ MUP solution yielded an $\mathrm{LRF}_{10}$ of $0.11 \pm 0.2$ after $1 \mathrm{~h}$ and $2.3 \pm 1.8$ after $24 \mathrm{~h}$ of exposure (Fig. 2).

\section{Discussion}

Our data provide evidence that OCT and CHG are effective components for disinfection of MRSA biofilms in vitro and that exposure to MUP at the standard concentrations in topical preparations up to $2 \%$ does not effectively inhibit the metabolic activity of MRSA biofilms, even after the prolonged exposure of $3.5 \mathrm{~h}$. The limited efficacy of MUP against the bacteria in biofilms has previously been described [35]. The biofilm probably provides a physical barrier for MUP so that only insufficient concentrations are reached in the bacteria themselves. Therefore, biofilm formation could influence development of resistance since bacteria in biofilms simply might have more time to adapt to low concentrations of MUP. However, further studies are needed to evaluate actual interactions of MUP with bacterial biofilms.

Nevertheless, our results show that MUP did not have significant bactericidal effects even on planktonic bacteria. In conclusion, MUP has mainly bacteriostatic effects, i.e., inhibition of bacterial growth and reproduction, and only
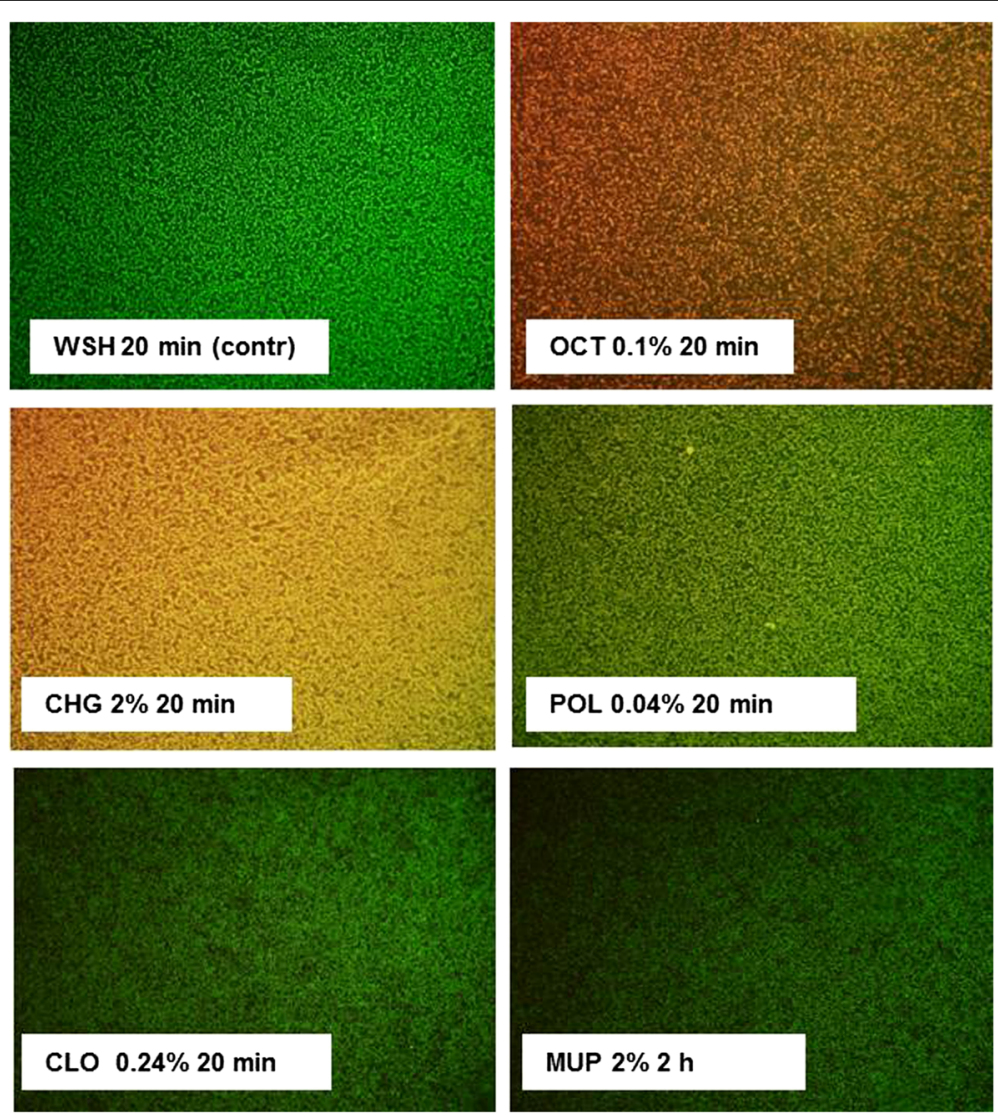

Fig. 3 Killing and permeation of MRSA-biofilms by antimicrobials Live/dead-staining using Syto 9 and propidium iodide stains of MRSA biofilms after exposure to WSH, $0.1 \% \mathrm{OCT}, 2 \% \mathrm{CHG}, 0.24 \% \mathrm{POL}, 0.24 \% \mathrm{CLO}$, and $2 \%$ MUP for varying exposure times. Green: bacteria in biofilm; red: bacterial cell death or defective bacterial cell integrity; yellow: dead bacteria in biofilm 
minor effects when bacteria are in biofilms. Biofilms might be the missing link in understanding the rapid development of resistance when MUP-based regimens are used routinely among general inpatient populations.

One limitation of our study is that we cannot estimate the fraction of MRSA strains that are strong biofilm formers. However, this issue should be addressed in future studies. As previously mentioned, one study on 810 nasal carriers of $S$. aureus and MRSA showed that all isolated MRSA strains were biofilm formers; however, only 34.6\% were medium to strong biofilm producers [7]. The larger the fraction of strong biofilm formers among MRSA strains, the more impact a change in the decolonization regimen will have.

\section{Conclusions}

The standard MRSA decolonization protocols at referral at our health care facility consist of 5 days of MUP treatment as nasal ointment and additional antiseptic washing of body and daily change of bed linen. Our data suggest that combining an MUP-based decolonization regimen with a disinfectant such as OCT or CHG could increase the efficacy of decolonization in patients colonized with biofilm-forming MRSA. In patients who failed the first decolonization attempt, one possible approach could be to change the 5 days of MUP treatment of the standard decolonization regimen to (1) two days of primary disinfection with either OCT or CHG as a nasal ointment followed by (2) three days of treatment with MUP for suppression of re-colonization. Obviously, this new regimen needs to be evaluated as randomized-controlled trial. Decolonization studies using OCT already show good decolonization rates (67\%); however, to our knowledge, no long-lasting effects with regards to re-colonization have yet been reported [36].

\section{Abbreviations}

CFU: Colony forming unit; CHG: Chlorhexidine; CLO: Chloroxylenol; LTHTh: Lecithin, Tween 80, histidine, and sodium thiosulfate neutralizing agent; MRSA: Methicillin-resistant Staphylococcus aureus; MUP: Mupirocin; OCT: Octenidine; POL: Polyhexanide; TSB: Tryptic soy broth; WSH: Water with standardized hardness

\section{Acknowledgements}

Language editing was done by Elsevier Language Editing Service.

\section{Funding}

We acknowledge financial support by Deutsche Forschungsgemeinschaft and Ruprecht-Karls-Universität Heidelberg within the funding programme Open Access Publishing.

\section{Availability of data and materials}

The data is not publicly available. Please contact the corresponding author for further information.

\section{Authors' contributions}

FG designed the study, analyzed and interpreted the data, and drafted the manuscript. BB contributed to the design of the study and conducted the experiments. ET contributed to the design of the study and wrote parts of the manuscript. NTM contributed to the design of the study, analyzed the data, and wrote the manuscript. All authors read and approved the final manuscript.

\section{Competing interests}

The authors declare that they have no competing interests.

Consent for publication

Not applicable.

Ethics approval and consent to participate

At Heidelberg University Hospital, all MRSA strains are routinely collected in the microbiology laboratory and stored at $-70^{\circ} \mathrm{C}$. The current study thus is descriptive of a bacterial collection of those isolates. No patient-related data were collected. Ethical approval was therefore not required. The study was a laboratory-based basic science study.

\section{Publisher's Note}

Springer Nature remains neutral with regard to jurisdictional claims in published maps and institutional affiliations.

\section{Author details}

${ }^{1}$ Department of Infectious Diseases, Heidelberg University Hospital, Im Neuenheimer Feld 324, 69126 Heidelberg, Germany. ${ }^{2}$ Division of Infectious Diseases - Department of Internal Medicine I, Tübingen University Hospital, Tübingen, Germany. ${ }^{3}$ German Centre for Infection Research (DZIF), Tübingen Germany.

Received: 17 January 2017 Accepted: 21 March 2017

Published online: 28 March 2017

\section{References}

1. Bhattacharya S, Bir R, Majumdar T. Evaluation of multidrug resistant staphylococcus aureus and their association with biofilm production in a Tertiary Care Hospital, Tripura, Northeast India. J Clin Diagn Res. 2015;9: DC01-04.

2. Nordmann P, Dortet L, Poirel L. Carbapenem resistance in Enterobacteriaceae: here is the storm! Trends Mol Med. 2012;18:263-72.

3. Nordmann P, Poirel L. The difficult-to-control spread of carbapenemase producers among Enterobacteriaceae worldwide. Clin Microbiol Infect. 2014; 20:821-30.

4. Mutters NT, Gunther F, Sander A, Mischnik A, Frank U. Influx of multidrugresistant organisms by country-to-country transfer of patients. BMC Infect Dis. 2015:15:466.

5. MRSA bacteraemia: annual data [https://www.gov.uk/government/statistics/ mrsa-bacteraemia-annual-data].

6. Ohadian Moghadam S, Pourmand MR, Aminharati F. Biofilm formation and antimicrobial resistance in methicillin-resistant Staphylococcus aureus isolated from burn patients, Iran. J Infect Dev Ctries. 2014;8:1511-7.

7. Rezaei M, Moniri R, Mousavi SGA, Shiade MJ. Prevalence of biofilm formation among methicillin resistance staphylococcus aureus isolated from nasal carriers. Jundishapur J Microbiol. 2013; 6(6):e9601.

8. McNeil JC, Hulten KG, Kaplan SL, Mason EO. Mupirocin resistance in Staphylococcus aureus causing recurrent skin and soft tissue infections in children. Antimicrob Agents Chemother. 2011;55:2431-3.

9. Thangamani S, Younis W, Seleem MN. Repurposing ebselen for treatment of multidrug-resistant staphylococcal infections. Sci Rep. 2015;5:11596.

10. Thangamani S, Mohammad H, Abushahba MF, Sobreira TJ, Seleem MN. Repurposing auranofin for the treatment of cutaneous staphylococcal infections. Int J Antimicrob Agents. 2016;47:195-201.

11. Thangamani S, Younis W, Seleem MN. Repurposing clinical molecule ebselen to combat drug resistant pathogens. PLoS One. 2015;10:e0133877.

12. Roche ED, Renick PJ, Tetens SP, Carson DL. A model for evaluating topical antimicrobial efficacy against methicillin-resistant Staphylococcus aureus biofilms in superficial murine wounds. Antimicrob Agents Chemother. 2012; 56:4508-10.

13. Gunther F, Wabnitz GH, Stroh P, Prior B, Obst U, Samstag Y, Wagner C, Hansch GM. Host defence against Staphylococcus aureus biofilms infection: phagocytosis of biofilms by polymorphonuclear neutrophils (PMN). Mol Immunol. 2009;46:1805-13

14. Dunne Jr WM. Bacterial adhesion: seen any good biofilms lately? Clin Microbiol Rev. 2002;15:155-66.

15. Davey ME, O'Toole GA. Microbial biofilms: from ecology to molecular genetics. Microbiol Mol Biol Rev. 2000;64:847-67. 
16. Meyle E, Stroh P, Gunther F, Hoppy-Tichy T, Wagner C, Hansch GM. Destruction of bacterial biofilms by polymorphonuclear neutrophils: relative contribution of phagocytosis, DNA release, and degranulation. Int J Artif Organs. 2010:33:608-20.

17. Watnick P, Kolter R. Biofilm, city of microbes. J Bacteriol. 2000;182:2675-9.

18. Donlan RM. Biofilm formation: a clinically relevant microbiological process. Clin Infect Dis. 2001;33:1387-92.

19. Donlan RM. Biofilms and device-associated infections. Emerg Infect Dis. 2001;7:277-81.

20. Donlan RM, Murga R, Bell M, Toscano CM, Carr JH, Novicki TJ, Zuckerman C, Corey LC, Miller JM. Protocol for detection of biofilms on needleless connectors attached to central venous catheters. J Clin Microbiol. 2001;39:750-3.

21. Gottenbos B, Busscher HJ, Van Der Mei HC, Nieuwenhuis P. Pathogenesis and prevention of biomaterial centered infections. J Mater Sci Mater Med. 2002;13:717-22.

22. Zimmerli W, Trampuz A, Ochsner PE. Prosthetic-joint infections. N Engl J Med. 2004:351:1645-54.

23. Costerton JW, Stewart PS, Greenberg EP. Bacterial biofilms: a common cause of persistent infections. Science. 1999;284:1318-22.

24. Cha JO, Yoo Jl, Yoo JS, Chung HS, Park SH, Kim HS, Lee YS, Chung GT. Investigation of biofilm formation and its association with the molecular and clinical characteristics of methicillin-resistant staphylococcus aureus. Osong Public Health Res Perspect. 2013;4:225-32.

25. Sai N, Laurent C, Strale H, Denis O, Byl B. Efficacy of the decolonization of methicillin-resistant Staphylococcus aureus carriers in clinical practice. Antimicrob Resist Infect Control. 2015:4:56

26. Abad CL, Pulia MS, Safdar N. Does the nose know? An update on MRSA decolonization strategies. Curr Infect Dis Rep. 2013;15:455-64.

27. Royal-College-of-Physicians-Ireland. Prevention and Control of Methicillinresistant Staphylococcus aureus (MRSA) National Clinical Guideline. 2013.

28. University-Clinic-of-Respiratory-and-Allergic-Diseases-Golnik-Slovenia. Guidelines to Control the Spread of MRSA. 2008.

29. Empfehlung der KRINKO beim Robert-Koch-Institut. Empfehlungen zur Prävention und Kontrolle von Methicillin-resistenten Staphylococcus aureusStämmen (MRSA) in medizinischen und pflegerischen Einrichtungen. Bundesgesundheitsbl. 2014; 57:696-732.

30. SWAB-Stichting-Werkgroep-Antibioticabeleid. Herziening SWAB richtlijn Behandeling MRSA dragers. 2012

31. Dow G, Field D, Mancuso M, Allard J. Decolonization of methicillin-resistant Staphylococcus aureus during routine hospital care: efficacy and long-term follow-up. Can J Infect Dis Med Microbiol. 2010;21:38-44.

32. Eigner U, Holfelder M, Oberdorfer K, Betz-Wild U, Bertsch D, Fahr AM. Performance of a matrix-assisted laser desorption ionization-time-of-flight mass spectrometry system for the identification of bacterial isolates in the clinical routine laboratory. Clin Lab. 2009;55:289-96.

33. Gunther F, Scherrer M, Kaiser SJ, DeRosa A, Mutters NT. Comparative testing of disinfectant efficacy on planktonic bacteria and bacterial biofilms using a new assay based on kinetic analysis of metabolic activity. J Appl Microbiol. 2017;122:625-33

34. Shanholtzer CJ, Peterson LR, Mohn ML, Moody JA, Gerding DN. MBCs for Staphylococcus aureus as determined by macrodilution and microdilution techniques. Antimicrob Agents Chemother. 1984;26:214-9.

35. Haisma EM, Goblyos A, Ravensbergen B, Adriaans AE, Cordfunke RA, Schrumpf J, Limpens RW, Schimmel KJ, den Hartigh J, Hiemstra PS, et al. Antimicrobial peptide P60.4Ac-containing creams and gel for eradication of methicillin-resistant staphylococcus aureus from cultured skin and airway epithelial surfaces. Antimicrob Agents Chemother. 2016;60:4063-72.

36. Danilevicius M, Juzeniene A, Juzenaite-Karneckiene I, Versinina A. MRSA decontamination using octenidine-based products. Br J Nurs. 2015; 24(S36):S38-40.

\section{Submit your next manuscript to BioMed Central and we will help you at every step:}

- We accept pre-submission inquiries

- Our selector tool helps you to find the most relevant journal

- We provide round the clock customer support

- Convenient online submission

- Thorough peer review

- Inclusion in PubMed and all major indexing services

- Maximum visibility for your research

Submit your manuscript at www.biomedcentral.com/submit

) Biomed Central 